\title{
Fertility Differentials and Educational Attainment in Portugal: A Non-Linear Relationship
}

\author{
Isabel Tiago de Oliveira \\ ISCTE - Instituto Universitário de Lisboa \\ Lisboa, Portugal \\ E-mail: isabel.oliveira@iscte.pt
}

\begin{abstract}
This analysis of the Portuguese case shows a non-linear relationship between the number of children and education in recent years. Using the data from ten years before this hypothesis was confirmed, and we can see that the general decline in Portuguese fertility within the last decade was due to the fertility decrease of the less educated people, although partly attenuated by the fertility increase of the upper social groups. The reasons for a non-linear relationship are discussed within the context of female employment rates and salary differentials by educational attainment. The main hypothesis is that differences in fertility are related to an 'education-work' effect amongst those in the less educated groups and to an 'education-income' effect amongst the more educated.
\end{abstract}

Key words: Fertility; education; female employment 


\section{Résumé}

L'analyse de cas de la situation au Portugal démontre une relation non linéaire entre le nombre d'enfants et le niveau de scolarité au cours des dernières années. Les données recueillies pendant les dix dernières années ont été étudiées avant de confirmer cette hypothèse; nous avons pu voir que le déclin général dans le taux de fécondité au Portugal pendant la dernière décade était causé par un déclin de fécondité chez les personnes moins éduquées; ceci a été partiellement atténué par une hausse dans le taux de fécondité dans les classes supérieures. Les raisons de cette relation non linéaire sont discutées dans le contexte des taux d'emploi des femmes et les différentiels de salaire selon les niveaux de scolarité. L'hypothèse majeure est que les différences dans les taux de fécondité sont reliés à un effet " scolarité-travail » parmi les groupes moins éduqués et à un effet "scolarité-salaire » parmi les classes mieux éduqués.

Mots clés: fécondité, scolarité, emploi des femmes

\section{Introduction}

Theoretical perspectives on the relation between education and fertility are mainly focused on the importance of female education upon female fertility. The most usual view supports the idea of a negative relation between education and fertility, that is, education's increase brings about a decrease in fertility. The basic argument is that higher educational attainments are associated with improved status, with higher income and a greater inclination towards career than towards family. This chain of interconnections brings out larger female employment and higher costs associated with maternal care.

Given the existent relationship between educational attainment and income, social status, women's participation in the labour force and social mobility between generations, etc., it is important to stress that the effect which education has on fertility cannot be singled out in isolation. For this reason, it is important to understand the relationship between education and fertility in its broader context.

In support of this view, we can point that recent research into the relationship between fertility and women's participation in the labor force shows that there has been a transformation in Western countries (Brewster and Rindfuss 2000; Sleebos 2003; Billari and Kohler, 2004). Analyses based on 
aggregate data from different countries show a negative association between fertility and women's employment until the 1980s and the change of this relationship since the mid-1980s, when the correlation becomes positive. In other words, at the present it is in those countries with greater female participation in the labour force that fertility tends to be higher.

Has the relationship between education and fertility also changed? In aggregate terms, we can find only one example of a positive correlation during the 1990s, when it had previously been negative (Sleebos 2003). However, there are a number of investigations based on individual data, particularly in the Fertility and Family Surveys and similar analyses, in which positive effects are established, even if they may be only partial conclusions, because only verified in some orders of birth (Kravdal 2001; Koppen 2006, Mencarini and Tanturri, 2006) ${ }^{1}$.

The evidence on the negative relation between education and fertility was confirmed by surveys conducted for the most part in developing countries (Tabutin and Schoumaker, 2004 and 2005). Fargues (1988) has also found this negative correlation in several Arab countries, but the author argues that education might have a contradictory effect in fertility since, in a first stage, education enlarges the differences between sexes and reinforces the traditional women status and only after that education is likely to increase the gender equality. The changing relation between education and fertility is debated in the final pages of this article and is a pertinent issue as Sleebos has showed for the OCDE.

\section{Portuguese Fertility in Recent Years}

As in other European countries, Portuguese fertility has, for a long time, shown a consistent decline. At the beginning of the 1960 s, the total fertility rate was approximately 3 children per woman. This rate declined gradually until the mid1990 s when it levelled out at 1.5 children. Since then, while the rate has oscillated slightly, it has largely remained at the same level.

This change in the total fertility rate has been accompanied by different tendencies in the evolution of the age at childbearing. From the beginning of the 1960 s to the mid-1980s there has been a decrease in the timing of fertility, and the mean age at childbearing has fallen from approximately 30 to nearer 27 years of age. Since the mid-1980s, there has been constant birth postponement, and the current mean age at childbirth is about 30 years. This postponement of birth is a relatively recent and yet consolidated tendency in Portugal as in all Europe. 
Figure 1. Total Fertility Rate and Mean Age at Childbirth, Portugal: 1960-2005

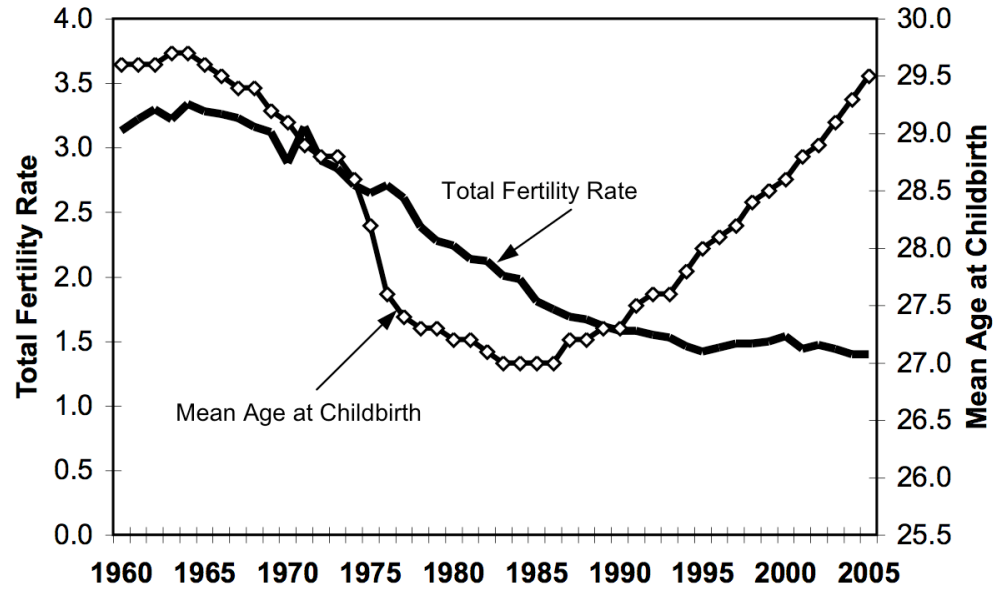

Sources: Population Census (1960, 1970, 1981, 1991, 2001); INE Population Estimates (2002 to 2005); and Demographic Statistics (1960-2005)

By 2005 the total fertility rate was 1.4 and the mean age at childbirth 29.5 years. As always, this average figure hides an important social diversity. For Portugal, two survey-based studies reveal some characteristics of fertility by educational attainment. The results of the 1997 Fertility and Family Survey show that the age at birth rises as education increases (INE, 2001). In another Portuguese study, Cunha (2005) analysed fertility by educational attainment and found that fertility decreased as the woman's level of education rose, until it reached a minimum at completed high school level. Following this there was a very slight rise in fertility for women with college degrees. 


\section{Data and Methods: The Period Total Fertility by Education Attainment}

Most studies on the fertility education issue are based on two methodologies: the correlation of aggregate data by region or the analysis of individual data from surveys.

It is not to usual compute the standard demographic indicator, such as the total fertility rate for the different educational groups, based in the macro data from the annual demographic statistics and the census. This approach as the advantage of working with the total population of births and women, being therefore free from the potential bias of non-representative samples.

This examination of the Portuguese case will analyse fertility at different levels of educational attainment and will present the distinct educational age fertility patterns, total fertility rates and mean ages at childbirth.

For 2000-01 it is possible to calculate the age specific fertility rates (incidence rates), and the subsequent demographic indicators according with educational attainment. In order to calculate the age specific fertility rates it was first necessary to make the census data and birth statistics compatible with one another, with the 2001 population census being related to the average of births during 2000 and 2001.

There are potential problems of compatibility between the levels of formal education in the census classified by the National Statistics Institute, and the self-classifications made by the individuals at the act of registering the birth. The potential bias can be caused by misreported births, especially in the lower education groups. To overcome this potential problem it is safer to aggregate the data in four levels of education corresponding to clear cuts within the education system, rather than use the more extensive classifications provided by the sources ${ }^{2}$.

The total fertility rate and the mean age at childbearing are demographic measures based on the synthetic cohort approach. Consequently, the values resulting from these calculations do not correspond to any real generation, but rather to a hypothetical generation that follows the fertility curve during the woman's life-cycle. The calculation of these indicators for different educational groups is not a standard procedure and raises some questions.

The total of the age specific fertility rates depends on educational attainment stability for the entire reproductive life. The idea of permanence can be separated into two phases:

1. If an individual has a determined educational attainment upon reaching the middle of reproductive life, he will tend to remain at that level of education. This is generally true since the social norms about usual life-cycle phases (education-work-marriage-family) are compelling. In the majority of cases, the birth of a child whilst 
the mother is in education will lead to the abandonment of studies and the beginning of the next phase. It is very difficult for someone with young children to return to education; for that reason, if a parent renews its schooling commitment it is generally only once their reproductive cycle has ended. ${ }^{3}$

2. Before a certain age, individuals are often students with constant changes between levels of education. In this situation, we are faced with the question of how to use age specific fertility rates to calculate accumulated fertility in a synthetic cohort up to the age of 25 or 30 years old.

The solution herein proposed is based on the mean age at which individuals complete their education in each educational group, as revealed in the Portuguese 1997 Fertility and Family Survey. Before this age, we assume that the total of the specific fertility rates is zero; after this age, the rates are summed up for the period corresponding to the difference between the average age at the completion of education and the final of the corresponding age group.

According to the 1997 Portuguese Fertility and Family Survey, the mean ages for completing education, were: 13.7, 18.8, 21.0 and 24.4 respectively for the women in the four educational groups. For example, if we use the mean age, women with tertiary education are considered not to be fertile before they reach 24.4 years of age, the mean age for completing this level of education: thus the age specific fertility rate from the 20-24 age-group is summed only for 0.6 years and not for 5 . The subsequent age fertility rates are summed for the usual 5 years.

More than conferring a real value to any group or generation, these figures have a synthetic and conjectural reading that permits an understanding of the fertility differences between different educational groups.

\section{Results: Timing and Fertility Level}

This is the most recent period for which it is possible to calculate accurately indicators for the four different educational levels being considered: up to sixth year; ninth year (lower-secondary); twelfth year (completed secondary); and tertiary education.

The timing of childbearing reveals a linear relationship with educational attainment - the greater the educational attainment, the older the mothers are. 
Considering all births, there is an observable difference with the mean age at childbirth: for women with only six years of education this age is 26.5 , whilst that for women with higher levels of education is 32.5. Furthermore, the figures for the age at the birth of the first child show the same pattern: for less educated women it is 24.1, rising as educational attainment increases - the mean age at which women with tertiary education have their first child is 31.2.

We may also note that the percentage of births taking place both before and after the woman reaches 30 years of age are very different across the four groups. Women with the lowest levels of education will have 74 percent of their children before they reach their thirtieth birthday. This proportion decreases as educational attainment rises: women with tertiary education have 71 percent of their fertility after that age.

\section{Table 1}

Mean Age at Childbirth (all Births and First Child), Proportion of Fertility before and after Thirtieth Birthday and Total Fertility Rate by Educational Attainment for Portugal: 2000-01

\begin{tabular}{l|c|c|c|c|c}
\hline \multicolumn{1}{c|}{ Education } & MAC & MAFC & $\begin{array}{c}\text { Up to Age } \\
30\end{array}$ & $\begin{array}{c}\text { After Age } \\
30\end{array}$ & TFR \\
\hline Six Years & 26.5 & 24.1 & 0.74 & 0.26 & 1.90 \\
Nine Years & 26.2 & 27.3 & 0.60 & 0.40 & 1.32 \\
Secondary & 31.0 & 29.5 & 0.44 & 0.56 & 1.29 \\
Tertiary & 32.5 & 31.2 & 0.29 & 0.71 & 1.36 \\
Total & 28.7 & 26.5 & 0.59 & 0.41 & 1.50 \\
\hline
\end{tabular}

Sources: 2001 Population Census and 2000-2001 Demographic Statistics

As for the fertility intensity, this indicator was computed as explained before: as the sum of the age specific fertility rates beginning at the mean age of conclusion of education.

The National Center for Health Statistics (Sutton and Mathews 2006) recommends the evaluation of the significance for differences in age fertility rates obtained from population statistics. In this case, the most important question is the significance of the differences between the most educated and the women with high school education. For the ages above 20 years (at younger 
ages the fertility rate of the highest educated can't be computed), the observed differences are always statistically significant, except in the older age group ${ }^{4}$.

Table 2

Estimated Fertility by Different Methods and Sources by Educational Attainment for Portugal: 2000-01, 1990-01 and 1997

\begin{tabular}{l|c|c|c|c|c}
\hline Education & $\begin{array}{c}\text { TFR } \\
2000-01 \\
\text { (base mean) }\end{array}$ & $\begin{array}{c}\text { TFR } \\
\text { 2000-01 } \\
\text { (base median) }\end{array}$ & $\begin{array}{c}\text { TFR } \\
1990-91\end{array}$ & $\begin{array}{c}\text { Adjusted } \\
\text { TFR } \\
2000-01\end{array}$ & $\begin{array}{c}\text { CFR } \\
\text { FFS) }\end{array}$ \\
\hline Six Years & 1,90 & 1.90 & 2.38 & 2.02 & 2.38 \\
Nine Years & 1.32 & 1.33 & 1.67 & 1.63 & 1.67 \\
Secondary & 1.29 & 1.30 & 1.09 & 1.49 & 1.09 \\
Tertiary & 1.36 & 1.38 & 1.22 & 1.55 & 1.22 \\
\hline
\end{tabular}

Sources: 1991 and 2001 Population Census; 1990-1991, 2000-2001 Demographic Statistics; and 1997 Fertility and Family Survey

The figures for the total fertility rate show a decline from the first to the second group, and then increases from the third to the fourth educational levels. Lesser educated women are the only ones who remain close to the threshold for generational substitution. Those in the second and third levels show only a slight decline in fertility, so it is more sensible to speak of stability. The final difference is in a positive direction: the fertility of better educated women is slightly above that of the preceding group.

We can also use the median age for completing education ${ }^{5}$ instead of the mean as the basis for the summation of the age fertility rates. The results are almost identical.

Since these are not typical results, it seems essential to try a confirmation of this tendency in other period. The same approach was consequently essayed stepping back for 10 years before and using similar data from the annual demographic statistics for the period 1990-91 and the 1991 population census.

A comparative analysis allows us to confirm the hypothesis of a nonlinear relationship between education and fertility in the beginning of the 90's: as education rises there is a decline in fertility levels, but for women with tertiary educations there is an increase in the total fertility rate.

Also, there is a significant evolution between the two moments: fertility differences are negative amongst those with the lowest educational attainment, 
but the fertility variation become positive for the women with secondary and tertiary education.

In sum, we can deduce that the general decline in Portuguese fertility within the last decade was due to the fertility decrease of the less educated people, which it was partly attenuated by the fertility increase in the upper social groups.

Nevertheless, total fertility rate is based on the demographic translation method, so it is necessarily, affected by changes in the mean age at childbearing (Ryder 1964, Bongaarts and Feeney 1998). These variations in the timing of childbearing are particularly different for the four educational groups causing different tempo effects. The observed postponement by educational group was used to compute the adjusted total fertility rate, according with the BongaartsFeeney method. ${ }^{6}$ The results reveal the same type of relation between fertility and education.

Instead of the total fertility rate, we can use a better indicator to grasp the intensity of fertility at the end of the reproductive life-cycle from real cohorts.

The 1997 Portuguese Fertility and Family Survey enable us to compare the fertility of several ages-groups with different levels of educational attainment. With the timing of childbearing being dependent upon educational attainment, the number of children by women ought to be calculated after the effects of birth postponement. A good indicator of fertility intensity is the total number of children that a woman ultimately has by the end of her reproductive life. In order to obtain a larger sample and ensure that the data refers to the most recent cohorts, we considered the mean number of children for women between 40 and 49 years. We can see that, the mean number of children declines at the first educational levels and subsequently increases as the parents' educational attainment also gets higher. In other words, data from the Portuguese survey suggests a non-linear relationship, although it is not statistically significant $(p=0.051)^{7}$ This is not an unambiguous confirmation of the differences found in the population. However since the p-value is so close to the usual $5 \%$ criteria, it can be considered indicative.

\section{Is there a Non-linear Relationship? And Why?}

This research has reached the clear and typical result about the timing of childbearing and it's relation with education: the greater the educational attainment, the higher will be the mean age at childbearing. However, for the fertility quantum and education relationship, the results are not so usual.

The total fertility rates, computed for the population, clearly decline across the first groups, and then show a slight increase amongst women with tertiary education. Nevertheless, the fertility from women who are in the final phase of their reproductive life, computed from the survey data, confirms this 
interpretation and demonstrates a U-shaped or an inverted-J relationship much more clearly.

It is important to note that these results are not typical. At the present time, it is impossible to know whether we are seeing a new tendency or whether we are dealing with a result that is purely circumstantial. Whatever the explanation may be, it is worthwhile to tap the full range of arguments.

The classical theory states that there is an inverse relationship between fertility and education. From this perspective, the greater the educational attainment, the lower will be female fertility. This is a view that is deeply rooted in the perspective of the relative cost of children's, which increases as the level of female education rises.

Such vision presupposes that there is a conflict between women's work and motherhood, which is amplified by the tendency of better educated women to have a career and to receive higher salaries.

In recent years however there has been a considerable growth in the number of women in the labour force and an increase in the number of children in pre-school education. This ought to lead to a reassessment of this idea.

With the effects of education, work and income being intrinsically linked, it is necessary to understand the effect of education in the context of the increased prevalence of working women, and the salary differences that are a consequence of educational attainment.

Table 3

Salaries and Female Employment according to Educational Attainment for Portugal: 2002

\begin{tabular}{l|c|c}
\hline \multicolumn{1}{c|}{ Estimates } & $\begin{array}{c}\text { Average Salary } \\
\text { (Euros) }\end{array}$ & $\begin{array}{c}\text { Women Employed } \\
\text { (\% 25-64 Years) }\end{array}$ \\
\hline Six Years & 611 & 60 \\
Nine Years & 770 & 77 \\
Secondary & 947 & 80 \\
Tertiary & 1815 & 87 \\
\hline
\end{tabular}

Sources: 1.) Average salary - Direcçào de Estudos, Estatistica e Planeamento do Ministério do Trabalho e Segurança Social (2002), Quadros de Pessoal, 2002, Table 98; 2..) Women employed - OCDE (2004), Education at a Glance, Table A10.1aEmployment Ratios and Educational Attainment (2002). 
Up to a certain level of academic qualification, it is possible that differences in educational attainment will have a negative effect on fertility for the simple reason that the probability of women working will increase, albeit in jobs in which educational skills makes little difference to salary levels. In such cases, greater educational attainment will have an effect on fertility, fundamentally by increasing the probability of women entering the labour force.

After a certain point, the situation shifts, and differences in educational attainment do result in improved salaries; simultaneously however, differences in the probability of working are not that significant: higher salaries - within the context of generally available and effectively used childcare - can result in a reduction of the relative cost of having children.

The figures, in table 3, corroborate the idea that improvements in the schooling level by those with lower levels of educational attainment are associated with the greater probability that woman will be working, although income gains are limited ${ }^{8}$ For those who have - at a minimum-completed high school, increases in education do result in clear income gains, while the percentage of women who work rises much less than the salaries. Thus, this data on salaries and work supports the hypothesis that differences in fertility are a function of educational attainment related to an 'education-work' effect amongst those in the less educated groups and to an 'education-income' effect amongst the more educated.

\section{Summary and Discussion}

The current fertility analysis for the European regions shows that birth postponement is a fundamental characteristic in the present trends of fertility. This delay element is particularly evident in both Southern and Eastern Europe: the regions in which we find the lowest total fertility rates in the last decade. Birth postponement has been the subject of comparative analyses of different European countries, resulting in the idea that higher levels of educational attainment and the extension in the duration of schooling are key factors in explaining birth postponement (Sobotka 2004; Kohler, Billari and Ortega 2002; Lesthaeghe and Willems 1999).

Within this context, it is crucial to question the final fertility rates for the different educational levels. And it is particularly useful to combine the macro data from the official statistics, with the micro data resulting from well designed surveys.

Portugal is an attention-grabbing case for analysis, since the general educational levels of the populations are considerably lower than in most European countries. However, Portugal has a higher percentage of working women and this element constitutes a distinctive and long-established feature of the Portuguese society. Additionally, it is also a country with policy oriented 
measures that promote the higher educational levels for the youngest and, very recently for the overall active population. As a result the current rates of enrolment in higher education, for the youngest, tend to close the gap towards other European countries.

Two main issues can be summarized in this research: first, the non linear relation between education and fertility; secondly, the reduction in the fertility of the lower educated groups, along with the inverse tendency in the most educated people.

The fertility-education differentials can depend on the demographic stage (Jeffery and Basu, 1996; Cleland, 2002). At the onset of fertility transition, the more educated are forerunners and the less educated tend to adopt contraception more slowly. As the situation progress, the new values and practices spread along the social pyramid, so in the end of transition the fertility-education differentials can fade away. This view is discussed by Boongarts (2003), who found no evidence that supports this leader-follower model in the DHS surveys from the 57 less developed countries, so he favours therefore the permanentdifference idea; but in the same paper, the author shows the results from the FFS in 10 European countries and, in general, educational attainment is negatively related with fertility. However, in two of these countries, Portugal and Greece, the relation is not linear: the least and the best educated women's have a higher number of children.

\section{End Notes}

1. Some studies of Finland, Germany and Austria show a globally positive relationship, independently of the order of birth, between education and fertility (Vikat 2004). Yet other studies indicate a positive relationship between education and desired fertility (Heiland, Prskawetz and Sanderson 2005), while another has shown that the field of education is also an influencing variable (Hoem, Neyer and Anderson 2006).

2. The aggregation in these four levels of education corresponds to clear cut points in the education system for the three highest groups (different current designations and often different study institutions). Moreover we aggregate in one group the lower levels of education, were misreport problems could be more significant. The computation of the parity specific fertility rates for the classification presented originally by the data sources reveal that this aggregation in four levels is the most reliable one.

3. The 2001 census shows that only $13.3 \%$ of the population aged $15-19$ was still studying at the second educational level. Above that age the percent is always below $1 \%$ within this educational grade. As for the high school level, $48.4 \%$ of the $15-19$ age group, $6.8 \%$ of the $20-24$ and $1.25 \%$ from the $25-29$ age group were still studying at this level. Above that age the percent is always below $1 \%$. Regarding the tertiary level in the census $10.6 \%$ of the 15 -

CSP 2009, 36.3-4: 347-362 
19 age group were still studying at this level, as well as $29.4 \%$ of the $20-24$ age group, and $7.8 \%$ in the $25-29$ age women. Within the next age groups the percentages are: $2.5 \%, 1.6 \%, 1.25$ and $0.7 \%$.

4. According to the NCHS the difference between the observed rates is statistically significant if it exceeds the result of:

$$
1.96 \times \sqrt{\text { rate }_{A}^{2} / \text { births }_{A}+\text { rate }_{B}^{2} / \text { births }_{B}}
$$

For the ages above 20 years the observed differences are always higher than the formula result. They are consequently all statistically significant, except in the older age group.

\begin{tabular}{l|c|c|c|c|c|c}
\hline & $\mathbf{2 0 - 2 4}$ & $\mathbf{2 5 - 2 9}$ & $\mathbf{3 0 - 3 4}$ & $\mathbf{3 5 - 3 9}$ & $\mathbf{4 0 - 4 4}$ & $\mathbf{4 5 - 4 9}$ \\
\hline Observed Difference & 7.4 & 12.4 & 29.0 & 16.8 & 2.8 & 0.0 \\
Formula Result & 1.3 & 1.8 & 2.5 & 1.8 & 0.9 & 0.3 \\
\hline
\end{tabular}

The differences between the women with tertiary education and the women with 9 years of education are even higher.

5. The median ages are: $12.5,18.5,20.5$ and 23.5 years in the same educational groups.

6. For 1990-91 the mean ages at childbirth were: 25.9, 27.3, 29.6 and 31.3 years old. So, birth postponement, in the last decade, was $0.61,1.89,1.36$ and 1.22 years for the four educational groups.

7. Given that the dimension of the four samples assembled for the various educational levels is quite different $(n=1083, n=101, n=52$ and $n=115)$ and the Levene test for the homogeneity of variances shows significant differences $(p=0.008)$, the Anova method holds no validity. Since the most important issue is if the difference between the higher educated women and the "middle" education groups, I will focus on that topic.

The two intermediate education levels are aggregate in one group (besides the size question they have a very similar mean number of children: 1.51 and 1.50). In order to test the difference in the mean number of children for independent samples: complete or incomplete high school education v.s. tertiary education, the t-test was used. The sample size is similar $(\mathrm{n}=153$ and $\mathrm{n}=115)$, the variances are not statistically significant $(\mathrm{p}=0.904)$, and the difference between the two means is not significant, although near significance (means of 1.51 v.s. $1.74 ; \mathrm{p}=0 \square 051$ ). 
8. Although it would also be interesting to explain male and female average salaries separately, the available data does not permit this disaggregate overview.

\section{References}

Becker, G. 1981. A Treatise on the Family, Harvard, Harvard University Press.

Billari, F. and Philipov, D. 2004. "Education and transition to motherhood: a comparative analysis of Western Europe", Vienna Institute of Demography Publications (www.oeaw.ac.at/vid/download/edrp_3_04.pdf)

Blossfeld, H. P. and Huinink, J. 1991 "Human capital investment or norms of role transition? How women's schooling and career affect the process of family formation", American Journal of Sociology, 97: 143-168

Bongaart S, J. and Feeney, G. 1998. "On the quantum and tempo of fertility", Population and Development Review, 24: 271-291

Bongaart S, J. 2003. "Completing the fertility transition in the developing world: the role of educational differences and fertility preferences", Population Council Working Papers (www.popcouncil.org/pdfs/wp/177.pdf)

Brewster, K. and Rindfuss, R. 2000. "Fertility and women's employment in industrialized nations", Annual Review of Sociology, 26: 271-296

Cleland, J. 2002. "Education and future fertility trends, with special reference to mid transitional countries, Expert Group Meeting on Completing Fertility Transition", United Nations Publications (www.un.org/esa/population/publications/completingfertility/RevisedCLELAN Dpaper.PDF)

Cunha, V. 2005. “A fecundidade das Famílias Portuguesas” in WALL, K. (editor), Famílias no Portugal, Lisboa, Instituto de Ciências Sociais.

Direcção de Estudos, Estatística e Planeamento do Ministério do Trabalho e Segurança Social (DEEPMTSS). 2002. Quadros de Pessoal de 2002, Lisbon, Ministério do Trabalho e Segurança Social.

Fargues, P. 1988. "La baisse de la fecondite arabe", Population, 6: 975-1004.

Jeffery, R. and Basu, A. 1996. Girls' schooling, women's autonomy and fertility change in South Asia, New Delhi, Sage Publications.

Heiland, F., Prskawetz, A. and Sanderson, W. C. 2006. "Do the More-Educated Prefer Smaller Families?", Vienna Institute of Demography Working Paper (http://mailer.fsu.edu/ fheiland/research.htm) 
Hoem, J., Nyer, G. and Anderson, G. 2006. "Educational attainment and ultimate fertility among Swedish women's born in 1955-59", Demographic Research, 14, article 165, (www.demographic-research.org)

Instituto Nacional de Estatistica (INE). 2002. XIV Recenseamento Geral da População, 2001, Lisboa, INE

INE. 2001. Inquérito à Fecundidade e Família, 1997, Lisboa, INE

INE. 1993. XIII Recenseamento Geral da População, 1991, Lisboa, INE

INE. 1984. XII Recenseamento Geral da População, 1981, Lisboa, INE

INE. 1973. $11^{\circ}$ Recenseamento Geral da População, 1970, Lisboa, INE

INE. 1966-2005. Estatísticas Demográficas, from 1967 to 2005, Lisboa, INE

INE. 1964. X Recenseamento Geral da Populaça, 1960, Porto, Manuf. Modesta Ine, 1960-1966, Anuário Demográfico, from 1960 to 1966, Lisboa, INE

Koppen, K. 2006. "Second births in western Germany and France", Demographic Research, 14, article 14, (www.demographic-research.org)

KravdaL, O. 2001. "The High Fertility of College Educated Women in Norway: An Artefact of the Separate Modelling of Each Parity Transition”, Demographic Research, 5, article 6, (www.demographic-research.org)

KravdaL, O. 2002. "Education and fertility in sub-Saharan Africa: Individual and community effects", Demography, 39: 233-250

Martin, S. 2000. "Diverging fertility among US women who delay childbearing past age 30", Demography, 37: 523-533

Mencarini, 1. and Tanturri, M. L. 2006. "Familles nombreuses et couples sans enfant : les déterminants individuels des comportements reproductifs en Italie », Population-F, 61 (4): 463-492

Mendes, M. F., Rego, C. and Caleiro, A. 2006. "Educação e Fecundidade em Portugal: as diferenças nos niveis de educação influenciam as taxas de fecundidade?" Departamento de Economia da Universidade de Évora WP (http://www.decon.uevora.pt/working papers.php?id=212)

OCDE. 2004. Education at a Glance, Paris, OCDE.

Rindfuss, R., Morgan, P. and Offutt, K. 1996. "Education and the changing age pattern of American Fertility”, Demography, 33: 277-290 
Ryder, N. 1964. "The process of demographic translation", Demography, 1: $74-82$

Sleebos, J. 2003. Low fertility rates in OCDE countries: facts and policy response, Paris, OCDE electronic publications (http://ideas.repec.org/p/oec/elsaaa/15en.html)

Sutton, P. D. and Mathews, T. J. 2006. Birth and fertility rates by Hispanic origin subgroups: United States, 1990 and 2000, National Center for Health Statistics. 21(57).

Tabutin, D. and Schoumaker, B. 2004. "La démographie de l'Afrique au sud du Sahara des années 1950 aux années 2000”, Population, 3-4: 521-621.

Tabutin, D. and Schoumaker, B. 2005. "La démographie du monde arabe et du MoyenOrient des années 1950 aux années 2000”, Population, 5-6: 611-724.

Vikat, A. 2004. "Women's Labour Force attachment and childbearing in Finland", Demographic Research, 3, article 8, (www.demographic-research.org) 